\title{
A Study Internet of Things Is A Revolutionary Approach for Future Technology Enhancement
}

\author{
G.Ananadharaj, K.Balaji
}

\begin{abstract}
The creation is pushing ahead on a quick leap, and the recognition goes to regularly developing innovation. One such idea is Internet of things with which robotization is never again an augmented simulation. IOT interfaces different nonliving articles through the web and empowers them to impart data to their locale system to computerize forms for people and makes their lives simpler. The paper shows what's to come difficulties of IoT „, for example, the specialized (network, similarity and life span, guidelines, insightful investigation and activities, security), business (venture, unassuming income model and so forth ), cultural (evolving requests, new gadgets, cost, client certainty and so forth ) and lawful difficulties (laws, guidelines, methodology, approaches and so on ). An area additionally examines the different fantasies that may hamper the advancement of Internet of things, security of information being the most basic factor of all. An idealistic way to deal with individuals in embracing the unfurling changes brought by IOT will likewise benefit in its development. Internet of Things (IoT) is a new paradigm that has changed the traditional way of living into a high tech life style. Smart city, smart homes, pollution control, energy saving, smart transportation, smart industries are such transformations due to IoT. A lot of crucial research studies and investigations have been done in order to enhance the technology through IoT. However, there are still a lot of challenges and issues that need to be addressed to achieve the full potential of IoT. These challenges and issues must be considered from various aspects of IoT such as applications, challenges, enabling technologies, social and environmental impacts etc. The main goal of this review article is to provide a detailed discussion from both technological and social perspective. The article discusses different challenges and key issues of IoT, architecture and important application domains. Also, the article bring into light the existing literature and illustrated their contribution in different aspects of IoT. Moreover, the importance of big data and its analysis with respect to IoT has been discussed. This article would help the readers and researcher to understand the IoT and its applicability to the real world.
\end{abstract}

Keywords: network, similarity and life span, guidelines , insightful investigation and activities, security.

\section{INTRODUCTION}

Manuscript received on April 01, 2021.

Revised Manuscript received on April 12, 2021.

Manuscript published on April 30, 2021.

* Correspondence Author

G.Ananadharaj, Assistant Professor, Department of computer science and applications, Adhiparasakthi college of arts and science, kalavai, tamilnadu, India.

K.Balaji*, Assistant Professor, Department of computer science Ranipettai arts, science \& management college, thenkadappanthangal. tamilnadu, India.

(c) The Authors. Published by Blue Eyes Intelligence Engineering and Sciences Publication (BEIESP). This is an open access article under the CC BY-NC-ND license (http://creativecommons.org/licenses/by-nc-nd/4.0/)
The expression "Internet of Things" was first utilized in 1999 by British innovation pioneer Kevin Ashton with regards to inventory network the executives. According to the meaning of Gartner "Internet of Things (IoT) is the system of physical articles that contain installed innovation to impart and detect or associate with their interior states or the outside condition".

The Internet of Things isn't just about associating gadgets to the web, yet in addition understanding the things' that are associated. The chance of Internet of things is specially critical or individuals with incapacities, asInternet of things advancements can bolster humanoid exercises at bigger scope like structure or society, as the gadgets can commonly co-work to go about as an absolute framework. IoT depends on web, security issues of web will moreover show up in IoT. Web of Things is quickly transforming into a reality. We can see the confirmation of it around us. Our contraptions are getting progressively clever consistently from cutting edge cell phones to splendid television to sharp vehicle to smart kitchen to keen city. The whole thing is presently getting associated with web. It interfaces all the things with innovation and an entirely different world for them to communicate with each individual with the assistance of web. Internet of things isn't only an idea yet can end up being an unrest in propelling innovation to change the ways of life of people by and large

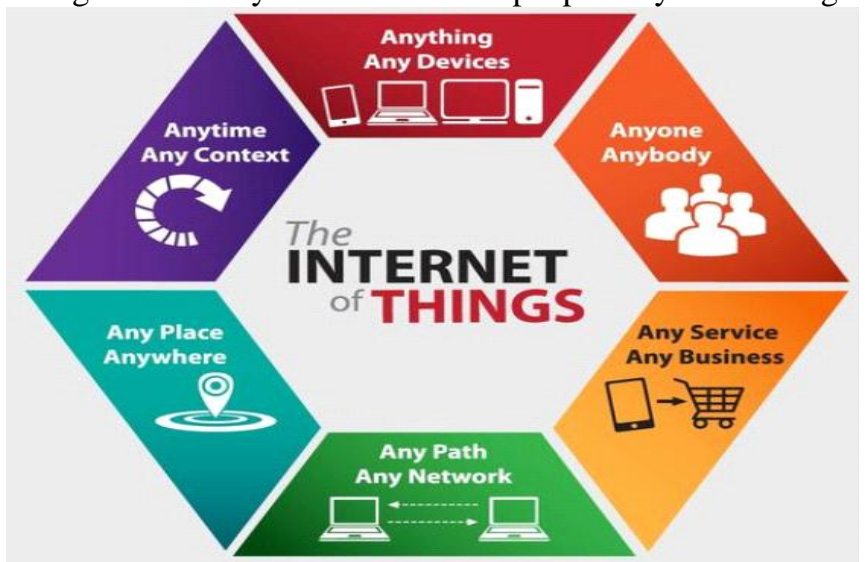

Figure1: Definition of Internet of Things

To comprehend it well, lease think about this situation of heading near a train. Here is a system of the web to which all the things like AC, caution, vehicles, espresso producer, maps, schedule, fuel marker and so forth are associated. Presently assume your gathering got postponed and will begin 45 minutes. Later in the first part of the day than booked, the framework will tell that you should rest 45 minutes. Late on account of the alteration.

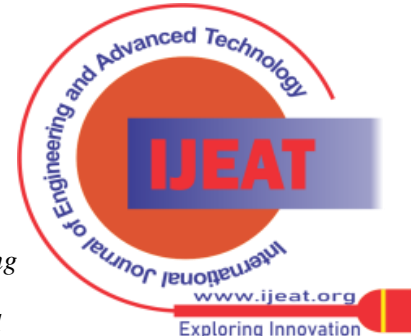


The framework additionally demonstrates the adjustment in train calendars and fuel planes. Though this is occurring, it is additionally conveyed to possessions like the alert which consequently rests for 5 minutes, the vehicle dissolves the ice that aggregated medium-term, and the espresso producer is prepared to make espresso following 5 minutes As showed by an examination done in 2018 - 2019 , there was an astonishing improvement in the appreciation then prioritization of Internet of things among people in just a single year. At the point when gotten some data about their excitement for IOT and their dedication with it, some care parameters seemed to have almost duplicated their rate regards from the latest year.

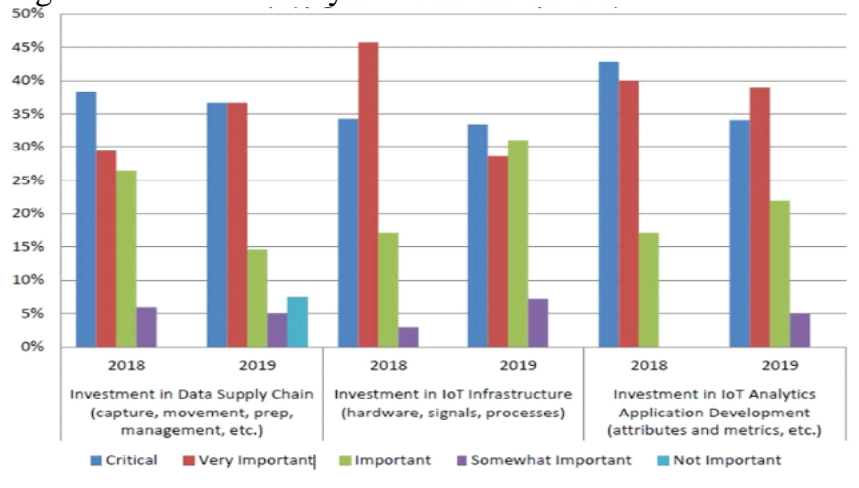

Figure 2: overview of understanding and prioritisation of IOT Technology

\section{APPLICATION OF IOT}

Potential utilizations of the web of Things are not just various yet in addition very different as they saturate into for all intents and purposes all parts of day by day life of people, establishments, and society. As indicated by , the utilizations of IoT spread expansive territories counting producing or the modern area, wellbeing division, farming, keen urban communities, security and crises among numerous others.

\section{1) Smart Cities}

As per, the IoT assumes an essential job in refining the brilliance of urban communities then improving overall foundation. Few of the IoT application regions in making savvy urban areas incorporate; astute transportation frameworks, savvy building, traffic clog squander administration, brilliant lighting, savvy stopping, and urban maps. This may incorporate extraordinary functionalities, for example, checking accessible parking spots inside the city, checking vibrations just as material states of extensions and structures, setting up sound checking gadgets in touchy pieces of urban communities, just as observing the degrees of walkers and vehicles. Fake Knowledge (AI) empowered IoT is used to screen, control and diminish circulation blockages in Smart Cities.

Likewise, web of things grants foundation of keen and atmosphere flexible street illumination and ID waste and waste compartments by keeping tabs of trash collection plans. Quick interstates can give advised messages and huge information, for instance, access to distractions contingent upon the climatic conditions or unexpected occasions like car over-burdens and disaster.

Use of internet of things to accomplish savvy urban communities would require utilizing radio recurrence distinguishing proof and sensors. A portion of the effectively evolved applications right now the Aware home and the Smart Santander functionalities. In the United States, some huge urban networks like Boston have foresees how to complete the Internet of Things in a huge segment of their structures stretching out from their halting meters, streetlights, sprinkler frameworks, and sewage grates are totally booked to be interlinked and associated with the web. Such applications will offer noteworthy leaps forward as far as setting aside cash and vitality.

\section{2) Healthcare}

Maximum social insurance frameworks in numerous nations are wasteful, unhurried and definitely inclined to mistake. This can undoubtedly be transformed since the social insurance area depends on various exercises and gadgets that can be computerized and upgraded through innovation. Extra innovation that can encourage different tasks like report distribution to numerous people and areas, record keeping and administering prescriptions would go far in changing the social insurance segment. A great deal of advantages that IoT application suggests the human services part stays generally classified into following of patients, staff, what's more, objects, distinguishing, just as verifying, people, what's more, the programmed assembling of information and detecting. Emergency clinic work process can be essentially improved once patients stream is followed. Also, verification and distinguishing proof diminish occurrences that might be hurtful to patients, record support also, less instances of confounding newborn children. Furthermore, programmed information assortment and transmission is indispensable in process mechanization, decrease of structure handling courses of events, computerized system evaluating just as therapeutic stock administration. Sensor gadgets permit capacities focused on patients, especially, in diagnosing conditions and benefiting constant data about patients' wellbeing markers .

\section{3) Agriculture and Water Management}

As indicated by, the IoT has the ability to reinforce furthermore, improve the horticulture area through inspecting soil dampness and on account of vineyards, observing the storage compartment breadth. IoT would permit to switch and save the amount of nutrients found in horticultural items, and control microclimate conditions so as to take advantage of the creation of vegetables and products of the soil quality. Moreover, concentrating climate conditions permits gauging of ice data, dry spell, wind changes, downpour or day off, controlling temperature and mugginess levels to forestall parasite just as additional microbial contaminants. With regards to steers, IoT can help with recognizing creatures that brush in open areas, recognizing impeding gases from animal fertilizers in ranches, just as controlling development conditions in posterity to improve odds of wellbeing also, endurance, etc. In addition, through IoT application in agribusiness, a great deal of wastage and deterioration can be evaded through appropriate observing strategies and the board of the whole agribusiness pitch. It likewise prompts better power and water control.

Published By:

Blue Eyes Intelligence Engineering DOI:10.35940/ijeat.D2387.0410421

Journal Website: www.ijeat.org
\& Sciences Publication

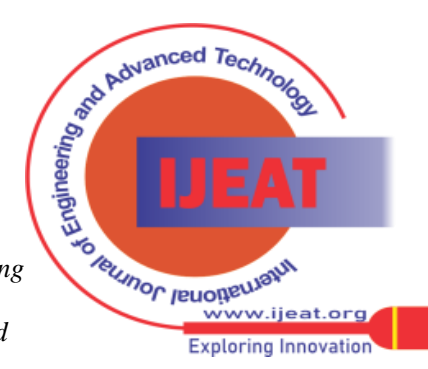




\section{4) Smart Living}

At the present time, can be applied in remote control devices whereby one can remotely turn contraptions on and off accordingly thwarting accidents similarly as saving essentialness . Other sharp home machines join ice chests close-fitting with LCD (Liquid Crystal Display) screens, engaging one to recognize what is available inside, what has over remained and is about slipping by similarly as what ought to be replaced. This information can in like manner be associated with a PDA application engaging one to find a good pace outside the house and right now what is required. In addition, garments washers can allow one to remotely screen apparel. In addition, a wide extent of kitchen contraptions can be interfaced through a mobile phone, hence making it possible to change temperature, as because of an evaporator. A couple of boilers which have a selfcleaning feature can be viably watched as well. To the extent prosperity in the home, IoT can be applied through alert structures and cameras can be acquainted with screen and separate window or gateway beginnings, therefore hindering interlopers.

\section{5) Environment}

Nature includes an imperative job inside all parts of life, from individuals, to creatures, winged animals and furthermore plants, are completely influenced by an unfortunate domain somehow. There have been various endeavors to make a sound domain in terms of taking out contamination and diminishing wastage of assets, yet the presence of enterprises, just as transportations squanders combined with wild and hurtful human activities are regular spot components which reliably harm the earth. Thus, the earth requires keen and creative approaches to help in observing and overseeing waste, which give a lot of information that powers governments to set up frameworks that will ensure the earth. Savvy condition procedures mix with IoT innovation ought to be made for detecting, following and appraisal of objects of the condition that offer potential benefits in accomplishing a feasible life and a green world. The IoT innovation permits watching and overseeing of air quality through information assortment from remote sensors across urban communities and giving nonstop geographic inclusion to achieve better methods for overseeing congested roads in significant urban communities. Moreover, IoT innovation can be applied in estimating contamination levels in water and thusly illuminate choices on water utilization. In squander the executives, which comprises of different sorts of waste, similar to synthetic concoctions and poisons being hindering to the earth and to individuals, creatures, and plants too, IoT can likewise be applied. This can be accomplished by natural security. Keen Environment Nature includes an imperative job inside all parts of life, from individuals, to creatures, winged animals and furthermore plants, are completely influenced by an unfortunate domain somehow. There have been various endeavors to make a sound domain in terms of taking out contamination and diminishing wastage of assets, yet the presence of enterprises, just as transportations squanders combined with wild and hurtful human activities are regular spot components which reliably harm the earth. Thus, the earth requires keen and creative approaches to help in observing and overseeing waste, which give a lot of information that powers governments to set up frameworks that will ensure the earth. Savvy condition procedures mix with IoT innovation ought to be made for detecting, following and appraisal of objects of the condition that offer potential benefits in accomplishing a feasible life and a green world. The IoT innovation permits watching and overseeing of air quality through information assortment from remote sensors across urban communities and giving nonstop geographic inclusion to achieve better methods for overseeing congested roads in significant urban communities. Moreover, IoT innovation can be applied in estimating contamination levels in water and thusly illuminate choices on water utilization. In squander the executives, which comprises of different sorts of waste, similar to synthetic concoctions and poisons being hindering to the earth and to individuals, creatures, and plants too, IoT can likewise be applied. This can be accomplished by natural security by methods for controlling mechanical contamination through momentary observing and the executives frameworks joined with supervision notwithstanding choice making systems. This serves to decrease squander through momentary observing and the executives frameworks joined with supervision notwithstanding choice making systems. This serves to decrease squander.

\section{DEVELOPMENT OF INTERNET OF THINGS OVER PAST YEARS}

The chart beneath portrays the development of IoT throughout the years. In 1992, just 1,00,000 individuals were utilizing IOT as an innovation. The number developed to a large portion of a billion people. Though 2009 denoted the IOT commencement, 2012 saw an abrupt increment in the utilization of IOT where the individuals utilizing IOT arrived at 8.7 billion, and nearby The quantity of clients has been becoming exponentially throughout the years arriving at 28.4 billion of every 2017. It is normal that the number will expand to 50.1 billion by 2020 .

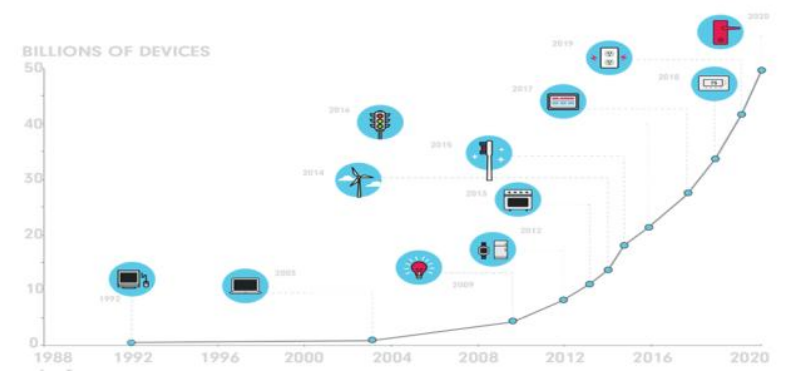

Figure3: Growth of Internet of Things over past years

\section{FUTURE OF IOT}

The vulnerability and commercial hazard is constantly currently in any new innovation. If there should be an occurrence of Internet of things, it is seen that a considerable lot of the threats are truly not present fairly they are contorted or misquoted. While it will require some investment to build up the IoT vision completely, the structure squares to begin the procedure are fit to be utilized.

Published By:
Eyes Intelligence Engineering

\& Sciences Publication

(C) Copyright: All Rights Reserved

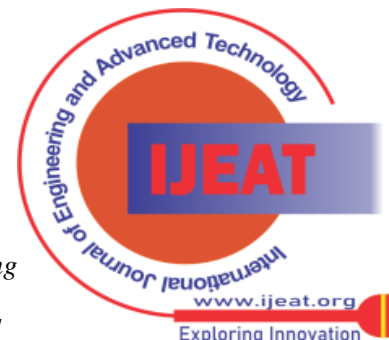


The significant prerequisites, for example, - equipment and programming resources are either accessible in a less amount or some of them are a work in progress; it is likewise a reality that: the safety and privacy worries of IoT gadgets are not appropriately tended to over past decade.

\subsection{IoT and Sensors}

The information created by maximum sensors are not utilized productively. To enable the innovation to advance, $62 \%$ overviewed producers accept that its usefulness can be improved by progressing investigation highlights. Additional preparation on examination device was likewise thought to be one route by $45 \%$ individuals. Greater versatility, registering force and ability to store information were additionally a few variables referenced by the producers.

\subsection{IoT and Mobile Data}

The adequacy of the hour of information from IoT sensors is poor. The information is commonly amassed by cell phones which have a basic work in IoT. The UI for IoT applications are given by the PDAs. In any case, they are not a pleasant other choice. In like manner, versatile systems and imparting contraptions have extraordinary drawbacks in locales, for instance, utilization of intensity, cost, unwavering quality and accessibility.Things being what they are, will the cell phones and cell interchanges will take a superior spot for consecutively Internet of things Applications? The appropriate response is supreme yes. Be that as it may, with respect to execution, availability, cost, transmission capacity, utilization of intensity and other key attributes, the IoT will want out and out all the more fluctuating and inventive assortment of equipment and programming arrangements.

\subsection{Volume of Data}

The creation of information of internet of things appeal is broad. The reality: The aggregate sum of information being produced by IoT applications isn't compulsory to be put away on cloud as it comprises of a great deal of pointless jabber created by gadgets in which no adjustment in condition is watched. The maximum critical test right now is the specific stockpiling of information on a cloud so that there won't be a capacity issue later on utilization of IoT gadgets. It additionally presumes that proper and right information will be given to the client while rest (trash) information delivered by IoT gadgets will be erased fittingly.

\subsection{IoT and Datacenters}

There is constantly steady contention that: Data in datacenters deals with all the procedures in IoT. Datacenter is completely a fundamental factor for the IoT. We should likewise concentrate on the unwavering quality of system which is utilized to run the IoT applications. Fast Internet is similarly significant as its presentation the functionalities like the dependable transmission of information, speedy conveyance of sensor information, getting subtleties from sensors to a cloud and the other way around.

\subsection{IoT as a Future Technology}

IoT is a development in the multidisciplinary world. Microcontrollers and Microprocessors, sensors and systems administration gadgets are a portion of the essential structure squares of the IoT and these are in across the board

Published By:

Blue Eyes Intelligence Engineering

\& Sciences Publication

(C) Copyright: All Rights Reserved use today. They have ended up being even more powerful today, even as they get tinier and increasingly moderate to make.

\subsection{IoT and protection and security}

Security and protection are the fundamental concerns while planning and creating IoT gadgets - and tending to these worries must be a high need. New innovation regularly has scope for misuse, and it's more astute to fathom the issue before it impacts protection and security, advancement or monetary improvement. It is an obligation of Manufacturers, norms associations and arrangement creators to address all the potential dangers to the item.

\subsection{IoT and limited vendors}

Open stage have reliably been an exhibited course for architects and vendors to build innovative hardware with constrained spending plans and assets . The direct of IoT applications has heterogeneous nature. Thus it requires a wide grouping of programming and gear. To makes all these IoT sections, there must be a full number of vendors open in the market.

\section{RESEARCH CHALLENGES}

For all the overhead probable utilizations of IoT, there ought to be certifiable possibility into the various zones to find the accomplishment of explicit applications and their handiness. Thus likewise with some other kind of improvement or progress, IoT experiences its difficulties and proposition that must be separated through to draw in mass social affair. Despite the way that the back and forth movement IoT empowering movements have unbelievably improved in the consistent years, there are so far various issues that require thought, right now prepared for new segments of research to be passed on out. Since the IoT thought follows from heterogenous headways that are used in recognizing, gathering, action, planning, interpreting, transmitting, telling, supervising, and taking care of data, a lot of research challenges will without a doubt develop. These investigation challenges that require thought have in this way spread over different research regions

\subsection{Technology Challenges}

a) privacy : Many IoT applications get to individual information however the security and insurance of individual information might be the one of the significant test for IoT engineers

b) Security: Iot makes an environment arrangement of constantly related contraptions granting over frameworks. The structure offers little control despite any security endeavors. This leaves customers exhibited to various sorts of aggressors. Extending the amount of different contraptions that assembles security issues.

c) Connectivity: Variability of bound and remote availability measures are required to empower distinctive application needs.

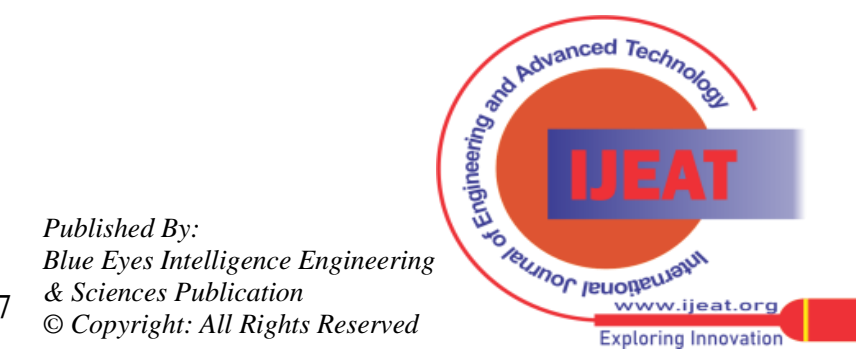


d) Scalability: Size of the frameworks keeps an eye on enormous in size, the arrangements ought to be adaptable. Additionally, any occasions the arrangements occur in stages and the design ought to have the option to scale up steadily without taking an excessive amount of overhead.

e) Flexibility: Numerous are stressed over the versatility of an IoT structure to arrange successfully with another. They worry over winding up with a couple of conflicting or catapulted systems.

f) Complexability : IoT is varying and complex framework. Any disappointment or bugs in the item or hardware will have authentic results. In reality, even power dissatisfaction can cause a lot of trouble.

g) Wireless communication: At the point when we come to vitality point, remote advancements, for instance, GSM, UMTS, Wi-Fi and Bluetooth are far less sensible. Various continuous WPAN floats as ZigBee are still a effort in development they take flimsy band width and devour less vitality.

\subsection{Business challenges:}

The principle issue is a significant inspiration for beginning, setting resources into, and managing any undertaking, without a full check technique for IoT we will have another air pocket, this model should fulfill the entirety of the prerequisites for a wide scope of online business; vertical markets, level markets, and customer markets. Regardless, this class is continually a sufferer of definitive and authentic assessment. Utilization of IoT advancements assumes a huge job to make a wellspring of extra pay to diminish the weight on the current correspondence framework.

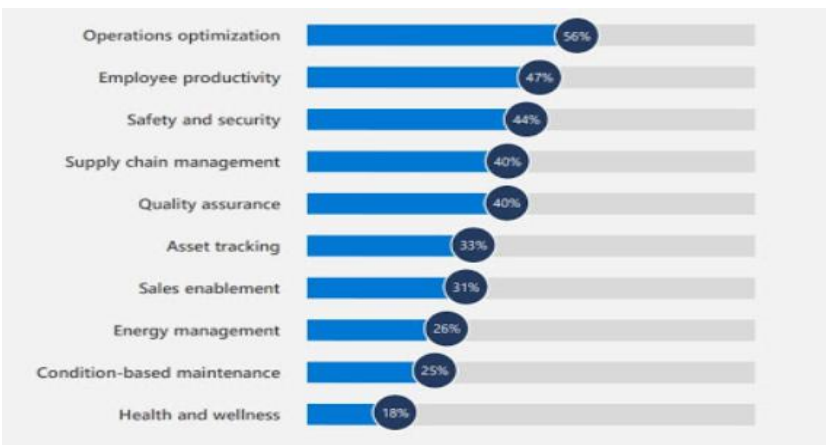

Figure4: Reasons Businessman are adapting IoT Solutions

\subsection{Society Challenges}

Considerate IoT from the customers and supervisors perspective is anything but a straightforward task for the associated reasons: Purchaser solicitations and requirements modification consistently. New uses for devices-and furthermore original tools-develop and grow hazardously quick. Concocting and reintegrating have features and limits that are costly and require gigantic theory and assets. The utilizations aimed at an IoT innovation stay developing and varying in unfamiliar way. User Assurance: Each of these issues could place an imprint in purchasers' need to purchase related things, which will protect the IoT after fulfilling its certifiable conceivable. Internet of things information remains a delicate information, whenever spilled can stretch the control of the framework in the assault's indicators. Henceforth they must take the solid and dependable innovation to verify how IOT information is being utilized. Professional arrangements and systems represent some social difficulties to IOT and management acts, and instructions present legitimate difficulties to its utilization.

\section{SECURITY AND PRIVACY CHALLENGES}

IoT makes every thing and person locatable and addressable which will make our lives much easier than before; however without a lack of confidence about the security and privacy of the user's data, it's more unlikely to be adopted by many [47]. So for its ubiquitous adoption, IoT must have a strong security infrastructure. Some of the possible IoT related issues are as followed:

\subsection{Unauthorized Access to RFID}

An unauthorized access to tags that contains the identification data is a major issue of IoT which can expose any kind of confidential information about the user so it needs to be addressed. Not just the tag can be read by a miscreant reader but it can even be modified or possibly be damaged. In this context, [47] summarized some of the real life threats of RFID which includes RFID Virus, Side Channel Attack with a cell-phone and SpeedPass Hack.

\subsection{Sensor-Nodes Security Breach}

WSNs are vulnerable to several types of attacks because sensor nodes are the part of a bi-directional sensor network as discussed in Section 4.2, which means other than the transmission of data, acquisition of data is also possible. [48] described some of the possible attacks that includes Jamming, tampering, Sybil, Flooding and some other kinds of attacks, which are summarized as followed: (1) Jamming obstructs the entire network by interfering with the frequencies of sensor nodes. (2) Tampering is the form of attack in which the node data can be extracted or altered by the attacker to make a controllable node. (3) Sybil attack claims multiple pseudonymous identities for a node which gives it a big influence. (4) Flooding is a kind of a DOS attack caused by a large amount of traffic that results in memory exhaustion.

\subsection{Cloud Computing Abuse}

Cloud Computing is a big network of converged servers which allow sharing of resources between each other. These shared resources can face a lot of security threats like Manin-the-middle attack (MITM), Phishing etc. Steps must be taken to ensure the complete security of the clouding platform [49]. Cloud Security Alliance (CSA) proposed some possible threats among which few are Malicious Insider, Data Loss, Accounts Hijacking and Monstrous use of Shared Computers etc [50] which are summarized as followed: (1) Malicious Insider is a threat that someone from the inside who have an access to the user's data could be involved in data manipulating. (2) Data Loss is a threat in which any miscreant user who has an unauthorized access to the network can modify or delete the existing data.

(3) Man-in-the-middle (MITM) is a kind of Account Hijacking threat in which the attacker can alter or intercept messages in the communication between two parties. (4) Cloud computing could be used in a monstrous ways because if the attacker gets to upload any malicious software in the server e.g.

Published By:

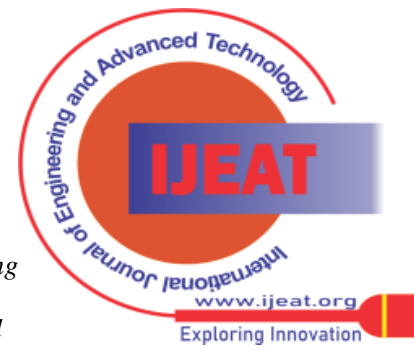


using a zombie-army (bot net), it could get the attacker a control of many other connected devices.

\section{CONCLUSION}

Internet of things is another internet submission will prompts a period of shrewd innovation where there exists thing-thing correspondence instead of human-human correspondence. With the IoT every single item right now handily followed and distinguished and can take choice autonomously. Systems and advancements are utilized in building ideas of Internet of Things,

for example, Radio recurrence Identification (RFID), Wireless sensor Networks (WSN) assume a significant job in IoT applications. IoT is utilized in medicinal services, industry, farming, transportation, security, utilities, training and different zones, while giving another biological system to application advancement. There are numerous protection and security gives that should be tended to. On the off chance that these issues are tended to, at that point Internet of Things will be worldwide mantra.

\section{REFERENCES}

1. Falguni Jindal, Rihabh Jamar,Prathamesh Churi," FUTURE AND CHALLENGES OF INTERNET OF THINGS “'International Journal of Computer Science \& Information Technology (IJCSIT) Vol 10, No 2, April 2018

2. P Parhana, MV Lakshmaiah, S Allaudheen, S Dastagiri, M Vijaya Saritha, "Internet of Things: Recent Applications and its Challenges", International Journal of Advanced Research in Electrical, Electronics and Instrumentation Engineering ISSN : $2278-8875$

3. Mahdi H. Miraz, Maaruf Ali," Internet of Things (IoT), Internet of Everything (IoE) and Internet of Nano Things (IoNT)"

4. Khan, R., Khan, S. U., Zaheer, R., \& Khan, S. (2012, December) Future internet: the internet of things architecture, possible applications and key challenges. In Frontiers of Information Technology (FIT), 2012 10th International Conference on (pp. 257260). IEEE.

5. Coetzee, L., \& Eksteen, J. (2011, May). The Internet of Thingspromise for the future? An introduction. In IST-Africa Conference

6. Mohamed Ali Feki, Fahim Kawsar, Mathieu Boussard, and Lieven Trappeniers, "The Internet of Things: The Next Technological Revolution," Computer, vol. 46, no. 2, pp. 24 - 25, February 2013

7. Rupali AM; Komal RH; Rutuja AG; Pranita PD; Yugandhara AT; et al. Internet of Things: Recent Applications and Challenges. IJESC 2017

8. Guicheng S; Bingwu L; The visions; technologies; applications and security issues of Internet of Things. 2011.

9. Li, S., Da Xu, L., \& Zhao, S. (2015). The internet of things: a survey. Information Systems Frontiers, 17(2), 243-259.

10. Giusto D; Iera A; Morabito G; Atzori L; The Internet of Things. 2010.

11. Rafiullah Khan, Sarmad Ullah Khan, Rifaqat Zaheer and Shahid Khan, "Future Internet: The Internet of Things Architecture, Possible Applications and Key Challenges," in Proceedings of Frontiers of Information Technology (FIT), 2012, pp. 257-260.

12. Guicheng Shen and Bingwu Liu, "The visions, technologies, applications and security issues of Internet of Things," in E Business and E -Government (ICEE), 2011, pp. 1-4.

13. Ling-yuan Zeng, "A Security Framework for Internet of Things Based on 4G Communication," in Computer Science and Network Technology ((ICCSNT), 2012, pp. 1715-1718.

14. "The "Only" Coke Machine on the Internet," Carnegie Mellon University, School of Computer Science.

15. M. Weiser, "The computer for the 21st century", e computer for the 21st century", Sci. Amer., 1991, pp.66 -75.

16. Jason Pontin, "Bill Joy's Six Webs," MIT Technology Review, 29 September 2005.

17. Kevin Ashton, "That 'Internet of Things' Thing", RFID Journal, 22 June 2009.

18. H.D. Ma, "Internet of things: Objectives and scientific challenge," in Journal of Computer Science and Technology, 2011, pp. 919-924. Proceedings, 2011 (pp. 1-9). IEEE.

19. De-Li Yang, Feng Liu and Yi-Duo Liang, "A Survey of the Internet of Things", in International Conference on E-Business Intelligence (ICEBI), 2010.

20. Harald Sundmaeker, Patrick Guillemin, Peter Friess, Sylvie Woelffl, "Vision and challenges for realising the Internet of Things," Publications Office of the European Union, 2010.

21. Gartner, Inc. It can be accessed at: http://www.gartner.com/newsroom/id/2905717.

22. "From the ARPANET to the Internet" by Ronda Hauben - TCP Digest (UUCP). Retrieved 2007-07-05 It can be accessed at: http://www.columbia.edu/ rh120/other/tcpdigest paper.txt.

23. Jian An, Xiao-Lin Gui, Xin He, "Study on the Architecture and Key Technologies for Internet of Things," in Advances in Biomedical Engineering, Vol.11, IERI-2012, pp. 329-335.

24. Lan Li, "Study of Security Architecture in the Internet of Things," in Measurement, Information and Control (MIC), 2012, Volume: 1, pp. 374-377.

25. "The Internet of Things," ITU Report, Nov 2005 [19] Wang Chen, "AN IBE BASED SECURITY SCHEME OF INTERNET OF THINGS," in Cloud Computing and Intelligent Systems (CCIS), 2012, pp. 1046, 1049.

26. Hui Suo, Jiafu Wan, Caifeng Zou, Jianqi Liu, "Security in the Internet of Things: A Review," in Computer Science and Electronics Engineering (ICCSEE), 2012, pp. 648-651.

27. Miao Wu, Ting-lie Lu, Fei-Yang Ling, ling Sun, Hui-Ying Du, "Research on the architecture of Internet of things," in Advanced Computer Theory and Engineering (ICACTE), 2010, pp. 484-487.

28. Xu Cheng, Minghui Zhang, Fuquan Sun, "Architecture of internet of things and its key technology integration based-on RFID," in Fifth International Symposium on Computational Intelligence and Design, pp. 294-297, 2012.

29. Debasis Bandyopadhyay, Jaydip Sen, "Internet of Things Applications and Challenges in Technology and Standardization" in Wireless Personal Communications, Volume 58, Issue 1, pp. 49-69.

30. Ying Zhang, "Technology Framework of the Internet of THings and Its Application," in Electrical and Control Engineering (ICECE), 2011, pp. 4109-4112 [25] Benjamin Khoo, "RFID as an Enabler of the Internet of Things: Issues of Security and Privacy," in Internet of Things (iThings/CPSCom), 2011, pp. 709-712.

\section{AUTHORS PROFILE}

G.Ananadharaj, Assistant professor and head, department of computer science and applications, Adhiparasakthi college of arts and science, kalavai, tamilnadu, india.

K.Balaji Student of department of computer science and applications, Adhiparasakthi college of arts and science, kalavai, Assistant professor and head, department of computer science Ranipettai arts, science \& management college, thenkadappanthangal. tamilnadu, india.

Published By:

Blue Eyes Intelligence Engineering

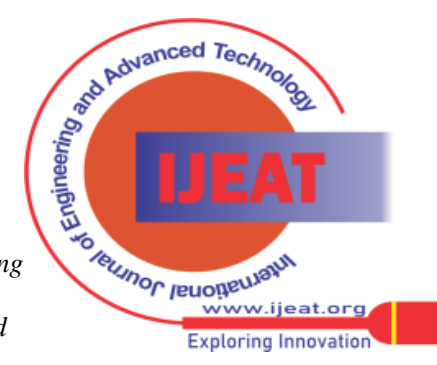

